\title{
Los cibermedios y los móviles: una relación de desconfianza
}

\section{Cybermedia and mobile phones: a relationship of distrust}

\author{
Alba Silva Rodríguez \\ Colaboradora (Grupo de Investigación "Novos Medios", \\ Universidad de Santiago de Compostela)
}

Fecha de recepción: 3 de abril de 2013

Fecha de revisión: 21 de junio de 2013

Para citar este artículo: Silva Rodríguez, A. (2013): Los cibermedios y los móviles: una relación de desconfianza, Icono 14, volumen 11 (2), pp. 183207. doi: $10.7195 /$ ri14.v11i2.586 


\section{Resumen}

El impacto de las nuevas tecnologías en el periodismo se remonta a principios del siglo XXI, cuando la introducción de Internet en las redacciones trajo consigo cambios que afectaron a los procesos de producción, emisión y recepción de la información. La digitalización obligó a las redacciones a reestructurarse y a los periodistas a repensar nuevas estrategias de distribución de contenidos. Este fenómeno de mutaciones, conocido con el nombre de convergencia, se intensifica en la actualidad con la llegada de los dispositivos móviles en el panorama comunicativo. Los teléfonos permiten que la producción y el consumo de información se realice, por primera vez, en cualquier lugar y mientras se está en movimiento.

La evolución tecnológica de las pequeñas pantallas situó a los dispositivos como una plataforma de gran importancia para la industria mediática. El objetivo es presentar las fortalezas, desafios y debilidades del impacto de la telefonía móvil en el ámbito comunicativo. Se presentan, además, las líneas de actuación que están siguiendo en este ámbito los principales medios de comunicación europeos.

\section{Palabras clave}

Comunicación móvil - Convergencia - Periodismo móvil - Prosumers - Cibermedios Móviles

\section{Abstract}

The impact of new technologies in journalism dates back to early the XXI century, when the introduction of the Internet brought in newsrooms changes affecting the processes of production, transmission and reception of information. Digitization forced to restructure newsrooms and journalists to rethink new content distribution strategies. This phenomenon of mutations, known as the convergence is intensified at present with the advent of mobile devices in the communications landscape. Smartphones allow the production and consumption of information is performed, for the first time, anywhere, while on the move.

The technological evolution of the small screens placed the devices as important platform for the media industry. The goal is present the strengths, weaknesses, 
challenges and the impact of mobile telephony in the area of communication. We present also the lines of action that are following the main European media in this area.

\section{Key Words}

Mobile Communication - Convergence - Mobile Journalism - prosumers - Cybermedia - Smartphones

\section{Introducción}

La expansión social de la telefonía móvil es un fenómeno en constante crecimiento. Los datos apuntan a que en la actualidad muchos países cuentan con más dispositivos que habitantes. Según datos de Comscore, la penetración de smartphones en la UE creció del 38\% en el 2011 hasta el 50\% (Comscore, 2011) y el tráfico en Internet móvil se duplica cada año. España, a su vez, ocupa la quinta posición dentro del conjunto de países europeos que más navega a través de los dispositivos móviles (Comscore, 2011).

\section{Tasa penetración líneas de telefonía móvil}

\begin{tabular}{|l|l|l|}
\hline Mobilens (2012) & Audiencia Smartphones & Penetración \% \\
\hline & & \\
\hline UE 5 & 126,347 & 52,4 \\
\hline Francia & 23,263 & 49,0 \\
\hline Alemania & 28,093 & 46,1 \\
\hline Italia & 23,836 & 49,7 \\
\hline España & 21,570 & 61,6 \\
\hline Reino Unido & 29,585 & 59,8 \\
\hline & & \\
\hline EE.UU & 116,481 & 49,8 \\
\hline Canadá & 11,720 & 54,0 \\
\hline & & \\
\hline
\end{tabular}

Figura 1: Tasa penetración líneas de telefonía móvil. Fuente: Elaboración propia traducida a partir de datos de Comscore, 2011

DOI: ri14.v11i2.586 | ISSN: 1697-8293 | Año 2013 Volumen 11 N² 2 | ICONO14 
Durante el 2011, España era el país con más teléfonos móviles por habitante, de tal forma que un $96 \%$ de los ciudadanos disponía, al menos, de un terminal. Según el último informe de Comscore, España lidera el índice de adopción de teléfonos inteligentes (smartphones) con algo más de un $66 \%$ de penetración (Comscore, 2013).

La popularización de los dispositivos móviles ha cambiado la forma en la que los usuarios consumen las noticias. Los dos grandes motores de consumo de los últimos años son el móvil y las redes sociales (Varela, 2012). Asimismo, el consumo de información a través de los dispositivos móviles crece constantemente. En los EE.UU un $15 \%$ de los usuarios accede a las noticias a través de sus móviles y en España esta cifra alcanza el 25\% (Comscore, 2011).

\section{Tráfico web desde dispositivos móviles}

\begin{tabular}{|l|l|}
\hline \multicolumn{2}{|c|}{ Porcentaje de tráfico web desde móvil, tablet y otros dispositivos } \\
\hline & \\
\hline Reino Unido: $16.4 \%$ & Dinamarca: $7.5 \%$ \\
\hline Irlanda: $11.5 \%$ & Alemania: $7.0 \%$ \\
\hline Rusia: $10.4 \%$ & Finlandia: $6.8 \%$ \\
\hline Noruega: $10.0 \%$ & Italia: $5.6 \%$ \\
\hline España: $9.7 \%$ & Bélgica: $5.1 \%$ \\
\hline Suíza: $9.3 \%$ & Francia: $5.0 \%$ \\
\hline Suecia: $9.2 \%$ & Portugal: $3.0 \%$ \\
\hline Países Bajos: $9.0 \%$ & Polonia: $2.2 \%$ \\
\hline Austria: $7.6 \%$ & Turquía: $1.8 \%$ \\
\hline
\end{tabular}

Figura 2: Tráfico web desde dispositivos móviles. Fuente: Elaboración propia traducida a partir de Comscore, Junio 2012

La venta de teléfonos móviles inteligentes se populariza con las mejoras de la red de banda ancha y con la introducción de Internet en las pequeñas pantallas. La vertiginosa expansión de esta tecnología hizo que su impacto llegara a superar al que tuvieron los ordenadores durante la década de los años 80. Este éxito y la difusión de la telefonía inalámbrica supusieron la apertura de un canal alternativo para la distribución de noticias. Con la incorporación de las pantallas en los 
teléfonos y gracias a la posibilidad de acceder a la red de redes, las empresas mediáticas observaron que estos aparatos tal vez podrían ser un incentivo de cara a la explotación de un nuevo modelo de negocio periodístico. Fue así como, debido a la integración de los servicios web en el móvil, el dispositivo adquirió una nueva dimensión en el ecosistema informativo digital llegando a plantearse la posibilidad de hablar de un nuevo medio de comunicación.

Fidalgo (2009) considera que "mañana conoceremos los medios a través de los teléfonos móviles" (p.122). Recuerda, tal y como apuntaba Ahonen, que "los móviles se convirtieron en el primer medio de comunicación personal" (p.123). En esta misma línea se sitúa Vacas Aguiar (2007) al afirmar que el "móvil no es solo un nuevo soporte de transmisión sino un nuevo medio" con nuevos formatos, sistemas de financiación y un nuevo lenguaje audiovisual derivado del tamaño de las pantallas y del carácter especialmente interactivo del terminal móvil.

Los teléfonos móviles suponen un importante reto para las empresas periodísticas a la hora de producir contenidos capaces de ser transmitidos en un nuevo contexto en el que la información se consume en movilidad. La sociedad necesita acceder a la información en cualquier momento y desde cualquier punto, aspecto que pueden satisfacer los móviles inteligentes gracias a su capacidad de procesamiento y acceso a la información desde cualquier lugar e instante (Rojo, 2008). Sánchez Valverde y Aguado Martínez (2010) consideran que el dispositivo móvil cumple una doble función: como plataforma de distribución o como herramienta de producción informativa.

Los nuevos contenidos en el ecosistema mediático digital se caracterizan por ser más "abundantes, baratos, amigables, sociales, personales e interactivos" (Varela, 2011: p.3). La cuarta pantalla (Cebrián y Flores Vivar, 2011 y Aguado y Martínez, 2008) tiene para muchos autores una serie de características intrínsecas que le permiten adaptarse a la nueva contorna así como poder cumplir con las características que demanda la sociedad. Señala Antonio Miguel Fumero (2010) que se trata de un dispositivo que refleja a la perfección la "hipermultifuncionalidad instrumental" y la complejidad del nuevo entorno tecnosocial que dibujan algunos pensadores (pp. 1-7).

Los teléfonos móviles han sido considerados como la "cuarta pantalla" o el "séptimo medio de comunicación de masas". La cuarta pantalla detrás de medios de comunicación históricos como el cine, la televisión o Internet y el séptimo medio

DOI: ri14.v11i2.586 | ISSN: 1697-8293 | Año 2013 Volumen 11 N² 2 | ICONO14 
después de la imprenta, las grabaciones, el cine, la televisión, la radio e Internet (Ahonen, 2008). Pero los dispositivos móviles tienen una peculiaridad en relación con todos los medios que les han precedido. Son los accesorios más privados y personales que poseemos hoy en día. La proliferación de los móviles y de otros medios portátiles ha desafiado la conceptualización tradicional de la relación entre la tecnología de la comunicación y el cuerpo. Los teléfonos móviles son exclusivos y únicos con respecto al resto de medios interactivos porque podemos llevarlos con nosotros a cualquier lugar y en todo momento.

Las ventajas de la telefonía móvil como soporte a través del cual transmitir información se resumen en las siguientes:

- Capacidad interactiva, adaptabilidad a las condiciones de consumo y al contexto de usuario

- Vinculación a la identidad y a la personalidad del usuario

- Permite incorporar contenidos producidos por los usuarios y contenidos producidos por instituciones u organizaciones mediáticas

- Valores de simultaneidad, secuencialidad (condición aperiódica de sus contenidos, que están más condicionados por el contexto de consumo y la identidad del usuario)

Los estudios de consumo muestran que los usuarios de noticias a través de teléfonos móviles responden a un arquetipo habitual. A través de los smartphones se realizan actividades paralelas como escuchar música, leer libros, jugar, leer la prensa, ver películas, etc.

La telefonía móvil está cambiando el panorama de los medios. En un contexto de crisis de la identidad de la prensa y de dificultades para el sector mediático en general lo móvil emerge y gana la batalla ante los medios tradicionales. En el sector publicitario, por ejemplo, la mayor parte de la audiencia la sostiene el móvil y el vídeo. La readaptación de los mercados se concentra en situar la atención a la fragmentación de las pantallas y las audiencias. Es por eso por lo que los smartphones también están modificando los patrones de consumo de los usuarios. La búsqueda móvil, el vídeo, las aplicaciones o las redes sociales son las actividades más consultadas desde los teléfonos móviles. En el ámbito publicitario, desde el 2011, el sector que más ha crecido ha sido el móvil, tal y como podemos comprobar en el siguiente gráfico:

ICONO14 | Año 2013 Volumen 11 N² 2 | ISSN: 1697-8293 | DOI: ri14.v1 1i2.586 

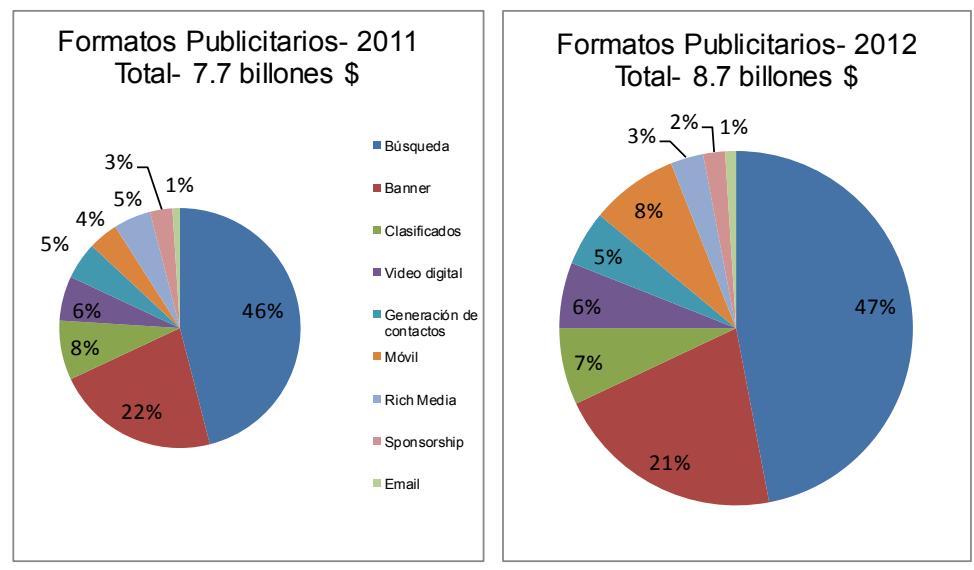

Figura 3: Sector de publicidad móvil. Fuente: Elaboración propia traducida a partir de datos de Blog Periodistas 21, Juan Varela (2012)

\section{Material y métodos}

Para dar cuenta de una visión general acerca de las incursiones que los principales medios de comunicación digitales europeos están haciendo en el ámbito de la comunicación móvil se seleccionaron una serie de medios de referencia que disponían de versión para dispositivos inteligentes. Se partió de una primera observación de todos los medios de comunicación on line considerados de referencia que presentaran versión móvil o versión específica, a través de una app adaptada a la interfaz de los terminales móviles.

La selección de los cuatro medios (The Guardian, Repubblica, Le Monde y El País) se basa principalmente en un criterio de exclusividad. Se trata de medios considerados de referencia en sus respectivos países. Esta terminología de "medios de referencia" fue adoptada por Merrill (1968), quien identifica al "periódico de calidad" con el "periódico de referencia" o el "periódico de élite". Se establece en el presente trabajo esta sinonimia como una garantía de homologación de los diferentes medios, tomando como pauta su prestigio en la matriz impresa, y siendo conscientes, a la vez, de que su cualidad como medios de referencia no se hace extensible a su nivel de difusión. Se tienen en cuenta también los datos de audiencia de los periódicos digitales escogidos de acuerdo con la información suministrada por la consultora Comscore (2013) así como la trayectoria de cada cibermedio en las plataformas móviles. Después de una primera aproximación a las diferentes edi- 
ciones móviles de los medios europeos se observa que se trata de los pioneros en el campo de la movilidad en los países correspondientes $\mathrm{y}$, por lo tanto, los que están aprovechando más las características que ofrece la nueva plataforma en cuestión.

Una vez definida la muestra, el análisis se centró en aspectos formales y comparativos con las ediciones webs, para poder dilucidar si existían o no cambios con respecto a la concepción de la información para la nueva plataforma comunicativa en función del soporte utilizado.

El estudio formal y de contenido partió de una metodología mixta: cualitativa y cuantitativa (análisis formal de los productos y análisis de contenido de algunas piezas informativas).

Para llevar a cabo esta simbiosis metodológica se creó una ficha de análisis que consistió en la evaluación de las siguientes unidades contextuales de las portadas de las versiones móviles de cada cibermedio: fecha y hora, posición en portada, distribución, uso de recursos multimedia e interactivos, autoría y participación. La finalidad principal consistía en observar los elementos estructurales de las versiones para móviles para establecer y asentar las tendencias adoptadas en un escenario del que todavía no existen referentes. Estos datos servirán para determinar la existencia o no de posibles formatos y definir las posibles líneas de actuación 0 estrategias de los diferentes medios en el nuevo escenario comunicativo.

Para complementar el estudio se aprovecharon los datos extraídos de un análisis de caso realizado en el año 2011 (Silva, 2011), centrado en los medios de comunicación on line gallegos, para contrastar dicha información con los datos proporcionados en el resto de medios europeos, con el fin de encontrar similitudes o divergencias al respecto.

\section{Resultados}

\subsection{La prensa en los dispositivos móviles}

Los populares mensajes de texto (SMS) enviados a través de los teléfonos móviles y los mensajes multimedia (MMS) que aparecieron un poco más tarde fueron los primeros ejemplos que enseñaron y demostraron que el teléfono podía concebirse como algo más que un mero dispositivo para hablar. En un período que se considera "pre-mediático" los contenidos que alcanzaron mayor popularidad fueron

ICONO14 | Año 2013 Volumen 11 N² | ISSN: 1697-8293 | DOI: ri14.v1 1i2.586 
los siguientes: consumo de videos, música, tonos de descarga, juegos, imágenes y fondos de pantalla, revistas, libros y anuncios (Scolari, Aguado e Feijoo, 2012).

La traslación de contenidos periodísticos a los dispositivos móviles pasó principalmente por las siguientes fases (Cebrián y Flores Vivar, 2011 y Canavilhas, 2009):

a) Adaptación (2003-06): En sus comienzos la información se vertía dentro de los parámetros formales y estructurales que aparecían en las ediciones web. Las bajas velocidades de acceso, la falta de referentes anteriores y el diseño de los dispositivos, con pantallas de pequeño tamaño y poca resolución, dificultaban la producción propia. En cuanto a la tipología de contenidos periodísticos en los móviles Sánchez y Aguado destacan la homogeneidad y la especificidad incipiente (2010). Durante esta época se popularizan las alertas. Surgen durante el año 2000 y el 2002. Relacionadas con un periodismo de servicios, los contenidos que le proporcionaban al usuario estaban ligados en un primer momento a la meteorología, a los deportes o a los eventos políticos, entre otros. Las alertas informativas fueron los primeros productos de distribución informativa a través de la telefonía móvil (Sánchez Valverde y Aguado, 2010). Los formatos que experimentaron mayor éxito fueron las alertas SMS enviadas a los abonados, mediante tecnología push y los contenidos disponibles en línea las 24 horas que el usuario consultaba por su propia iniciativa (tecnología pull). Las alertas destacaban por su estilo breve y el valor de su inmediatez, características que determinaron que estas constituyeran un contenedor de la información periodística en los primeros albores de la comunicación móvil. El formato de las alertas presenta similitudes con la información de servicios. Canavilhas (2009) alude a que los formatos informativos iniciales estaban más próximos a la naturaleza del receptor (el móvil) que al emisor (periódicos, radios y televisiones) en contrapartida a lo que sucedía en los comienzos del periodismo en la Web.

b) Fase de autonomía (2007-10): Coincide con la introducción de Internet móvil. Los contenidos adquieren una identidad propia. Comienza a emerger una estructura adaptada al soporte y concebida a partir de una sola columna de texto acompañada de fotografías. Las versiones son ligeras y fáciles de bajar. Surgen con la mejora de la conectividad y la llegada de la banda ancha. El proceso de convergencia de Internet con los dispositivos móviles fue lento y temeroso en un primer momento. Temeroso porque las operadoras de telefonía veían como de esta manera podía peligrar su negocio sustentado en la comunicación por voz después de muchos años

DOI: ri14.v1 1i2.586 | ISSN: 1697-8293 | Año 2013 Volumen 11 N² 2 | ICONO14 
y lento por las dificultades en la penetración de la banda ancha en determinados puntos del territorio español. La consolidación de los smartphones (Costa, 2008) y el desarrollo y modernización de los dispositivos ayudó a extender la accesibilidad.

El iPhone de Apple supuso un revulsivo para la socialización de los dispositivos móviles como soporte comunicativo y, especialmente, en lo que tuvo que ver con la búsqueda de nuevos usos comunicativos en los terminales (Ruíz del 0lmo, 2010). El teléfono de Apple hizo posible subsanar todos los males de la industria de fabricación de los dispositivos móviles (Fumero, 2010). El estudioso portugués Antonio Fidalgo adelantaba en el 2009 que los móviles inteligentes serían en un período corto de tiempo la principal fuente de acceso a las noticias (Fidalgo, 2009). Con el iPhone se impuso la era de las aplicaciones (apps). Esto trajo consigo una mayor interactividad de los usuarios con sus dispositivos y una navegación contrapuesta a la de la Web en la que, "frente un Internet fijo, articulado sobre la navegación libre bajo la lógica de archivos y programas, se perfilaba un Internet móvil articulado sobre el acceso a servicios bajo la nueva lógica de aplicaciones y funcionalidades (Aguado, 2012). Habla Aguado de cuatro factores clave que impulsaron la tendencia a la fusión entre contenidos y aplicaciones (2012):

1. Consolidación de las tiendas de aplicaciones como modelo de negocio dominante en el ecosistema móvil. Las aplicaciones provocaron una gran innovación en el entramado de la comunicación móvil. Dejaron de ser concebidas como simples herramientas para pasar a formar parte de la distribución de contenidos. Es por eso por lo que estos autores proponen reformular la anterior categorización que separaba aplicaciones (asociadas al hacer, desde su punto de vista práctico) de contenidos (relacionados con el saber, con el conocimiento) y referirse a las aplicaciones móviles como la interfaz que conecta a los usuarios con los contenidos para saber y con las herramientas para hacer (Scolari, Aguado y Feijoo, 2012).

2. Necesidad de los productores de contenido de ofrecer un valor añadido suficiente que justificara su coste de acceso al servicio

3. Nuevas modalidades de ingreso por contenido: los "freemium" o "in- app purchase", que implican el pago por contenidos o productos puntuales dentro de las aplicaciones gratuitas

c) Fase de emancipación (2011- Actualidad): Este último período, que corresponde con el actual, nace justo en el momento de expansión de los teléfonos inteligentes smartphones y con la popularización de la red 3G. Es aquí cuando surgen las

ICONO14 | Año 2013 Volumen 11 N² | ISSN: 1697-8293 | DOI: ri14.v1 1i2.586 
aplicaciones propias para acceder a los contenidos de los medios de comunicación y también las widgets. Se trata de pequeñas aplicaciones informáticas integradas en la interfaz del usuario móvil que suponen un salto cualitativo con respecto a los portales informativos (Sánchez y Aguado, 2010). Es esta la etapa del contenido cross media. Los usuarios son programadores y gestores de información.

Juan Miguel Aguado (2012) equipara las fases evolutivas que experimentaron los contenidos presentados en las plataformas móviles con el progreso que sufrió la propia tecnología. Así, en un primer momento en el que primaba la información adaptada el contexto tecnológico estaba determinado por el dominio de operadores y fabricantes, con la inclusión del GPS y de la red 3G en el 2005 y 2006 respectivamente. En este período el dispositivo móvil actúa como soporte aunque comiencen a salir al mercado dispositivos con más memoria que incorporan nuevas funcionalidades para representar los contenidos multimedia.

Sería en la segunda fase cuando, con el fenómeno del iPhone y con la plataformización y la emergencia de aplicaciones y de herramientas de geolocalización, el móvil alcance la categoría de medio.

Los datos avalan que los usuarios consumen mucha información a través de los dispositivos móviles y que además utilizan diferentes dispositivos para acceder a los noticias en diferentes en función de diversos momentos del día.

A pesar de su amplia expansión y de las posibilidades que brinda esta nueva plataforma para explotar nuevos géneros y formatos periodísticos la tendencia observada en algunos estudios de caso realizados (Silva, 2011, 2012) muestran que los medios de comunicación se están introduciendo muy lentamente en el nuevo contexto de la movilidad. En relación a la plasmación de contenidos hacia el nuevo soporte se comprobó que los cambios se centran principalmente en la estructuración de la información sin prestar demasiada atención a la producción de contenidos específicos o a la experimentación de nuevas formas de expresión en la "cuarta pantalla".

\subsection{Los dispositivos móviles y la prensa gallega}

Los medios gallegos comenzaron paulatinamente, desde el 2009, a adaptar 0 trasladar sus versiones web a los dispositivos móviles. La corta trayectoria en este campo nos permite estudiar cuales son los retos a los que deben enfrentarse los

DOI: ri14.v11i2.586 | ISSN: 1697-8293 | Año 2013 Volumen 11 N² 2 | ICONO14 
productores de contenido, tanto desde el punto de vista del diseño como lo que tiene que ver con los contenidos.

Después de observar detenidamente y a partir de una ficha de análisis en la que analizaron los elementos hipertextuales, multimedia e interactivos presentes en las ediciones para móvil de todos los medios gallegos se concluyó que la distribución de las páginas es uno de los aspectos que definen las señales de identidad de las nuevas versiones. En el campo estético y formal serían estos los aspectos diferenciales con los que cuenta la plataforma móvil y desde el punto de vista de los contenidos se descubrió que emerge una tendencia al localismo. Esta predisposición se asocia a la estrategia SoLoMo (Social, Local, Móvil), principalmente para los medios locales, para el futuro del negocio.

La estructuración de los menús de página destaca, en su mayoría, la sección "lo$\mathrm{cal}^{\prime \prime}$, aspecto que denota la incidencia que la información de proximidad tiene en la nueva plataforma. Este aspecto es especialmente relevante en el caso de la prensa gallega. Los resultados de la investigación avalan que la sección de local aparece reflejada en más ocasiones en la página principal de las versiones para teléfonos (un 33\% de los casos analizados) que en las ediciones web (un 11\%). Este hecho nos indica que el localismo es una de las principales bazas con las que cuenta esta nueva plataforma.

Además de la inclinación por el localismo se detectó que la actualización de los contenidos cobra especial relevancia en el terreno de la comunicación vía móvil. La preocupación por la renovación de los acontecimientos se deja notar bajo los epígrafes de actualización que acompañan a las noticias.

En contraposición, existe una serie de deficiencias o carencias a nivel formal y de contenidos. Las informaciones en las versiones para móvil no aparecen destacadas bajo ningún tipo de indicador. Se mezclan con las secundarias presentando idéntico formato y tamaño, algo que contrasta con el tratamiento que reciben en la página web.

Uno de los puntos más destacados que se desprenden de este análisis se refiere a los datos extraídos con respecto a las firmas de las noticias. Aunque si existe un número considerable de noticias de elaboración propia hay muchas informaciones publicadas sin ningún tipo de firma. Este es un aspecto que indica la falta de confianza depositada en los móviles como plataforma de contenidos, tanto por los medios como por los periodistas, que no exigen la aparición de sus nombres al lado

ICONO14 | Año 2013 Volumen 11 N² | ISSN: 1697-8293 | DOI: ri14.v1 1i2.586 
de las informaciones que elaboran. Esto va ligado también a los fotógrafos. Resulta revelador ver como las mismas imágenes difundidas con firma en la web se plasmen en las versiones móviles sin referenciar su autoría. Este detalle avala la poca consideración y trascendencia que tiene para los profesionales la nueva plataforma, como también se manifiesta en el insignificante porcentaje de medios que, en su versión móvil, ofrecen direcciones a través de las cuales poder contactar con los autores de las piezas periodísticas.

Son todas estas razones las que llevan a concluir que los medios gallegos ven los móviles como un soporte secundario en todos los sentidos. Están en ellos porque así lo dictan los tiempos pero no le dan el valor ni la utilidad que tienen como plataforma a través de la cual trasladar información a los usuarios. Esta situación lleva a pensar en el futuro que queda por labrar en el campo de las versiones móviles de los medios de comunicación en Galicia. Quizás el problema resida en la concepción que tienen los medios del futuro de la comunicación. Adaptarse a los cambios tecnológicos es bueno siempre y cuando no se quede solo en eso, en una simple adaptación. La clave está también en la creación y en la innovación así como en saber aprovechar los recursos y utilidades que ofrecen los nuevos soportes. Estamos ante un nuevo desafío, fruto de una transformación social, que sitúa al móvil en un nuevo escenario como es el periodismo.

\section{Versión Web A Nosa Terra}

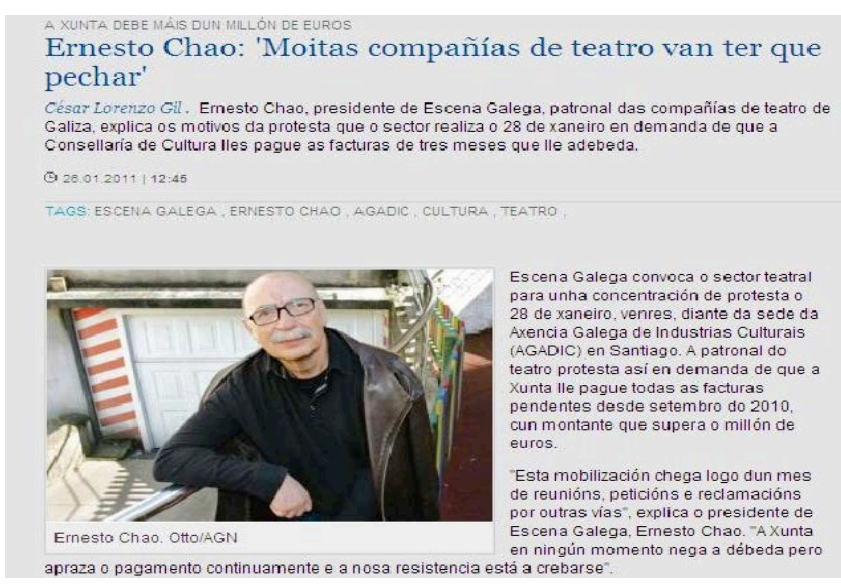

DOI: ri14.v11i2.586 | ISSN: 1697-8293 | Año 2013 Volumen 11 N² 2 | ICONO14 
Versión Móvil A Nosa Terra

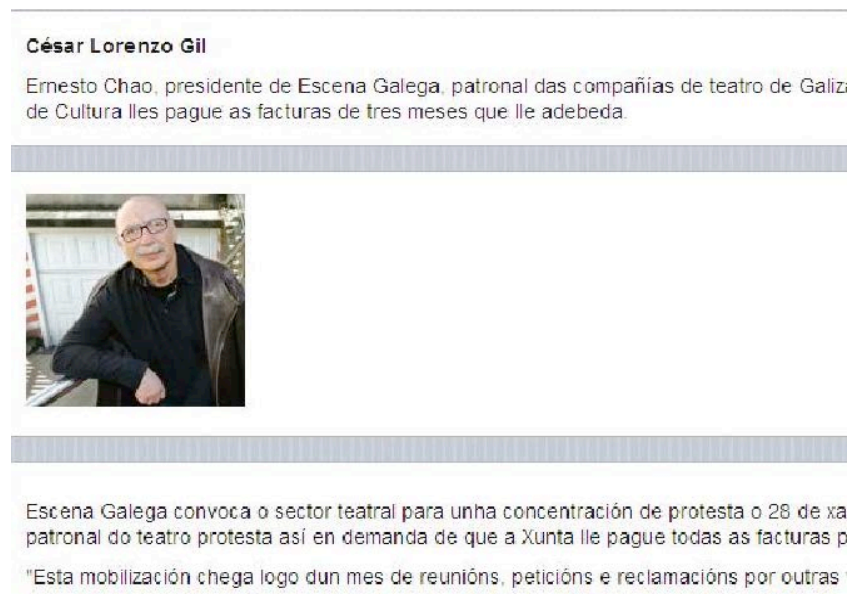

Figura 4: Autoría en versiones web y móvil de A Nosa Terra. Fuente: Elaboración propia

a partir de las páginas web y móvil de A Nosa Terra (2011)

Probablemente el análisis que hacía Bozckowski en su tiempo cuando estudiaba los primeros pasos de la inmersión de los medios en la Web no se aleje demasiado de la realidad actual que define a la información a través de los dispositivos móviles. Este autor decía que "los medios eran una especie de colonizadores que venían pisando territorio desconocido y que se asentaron en la red para tener una presencia allí, definiendo el mapa del territorio y determinando sus fronteras. Llevaban sus antiguos productos, creando otros nuevos y ofreciendo sus mercancías a clientes antiguos y nuevos" (2006). Este último aspecto, que parece ser olvidado por los medios gallegos, es de vital importancia a la hora de orientar estrategias de producción de contenidos vía móviles.

A continuación se plasman ejemplos de la estrategia de distribución multiplataforma de los cibermedios más representativos a nivel europeo. Como se puede comprobar, la tendencia adoptada es muy similar a la del caso gallego.

\subsection{Los dispositivos móviles y la prensa europea}

Como se puede observar, en este caso, el título de la noticia es idéntico tanto en la edición web como en la móvil. También el contenido de la información completa no varía en absoluto.

ICONO14 | Año 2013 Volumen 11 N² 2 | ISSN: 1697-8293 | DOI: ri14.v1 1i2.586 
Version Móvil The Guardian

Version Web The Guardian

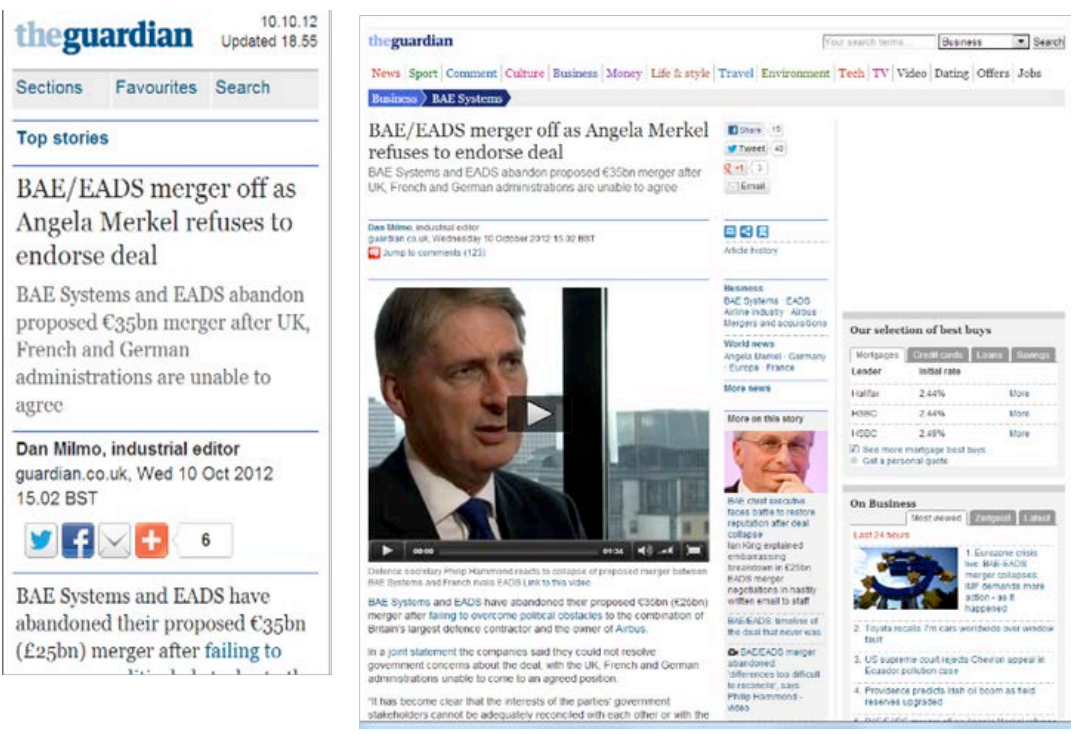

Figura 5: Estructura web y móvil de The Guardian. Fuente: Elaboración propia a partir de las páginas web y móvil de The Guardian

Versión Móvil El País

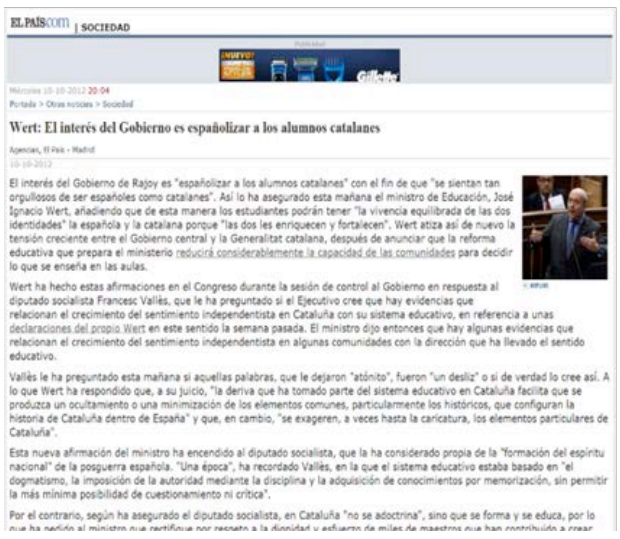

Versión Web El País

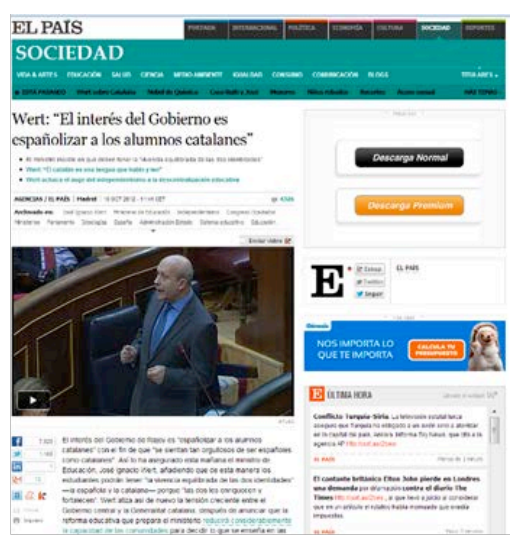

Figura 6: Estructura web y móvil de El País. Fuente: Elaboración propia a través de app móvil y la web de El País 
Versión Móvil Le Monde

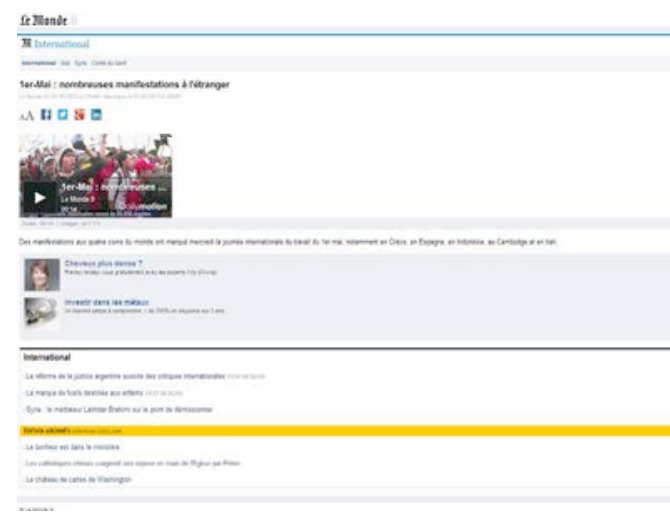

Versión Web Le Monde

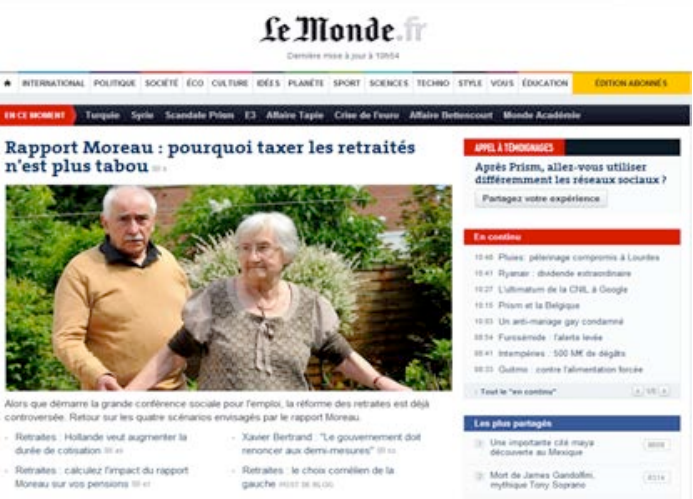

Figura 7: Estructura web y móvil de Le Monde. Fuente: Elaboración propia a través de app móvil y la web de Le Monde

En los cuatro medios analizados se observaron diferencias con respecto a las estrategias que los cibermedios adoptan a la hora de presentar sus contenidos en la plataforma móvil. En todos los casos las informaciones que aparecen destacadas en portada se distribuyen a partir de secciones aunque en el caso de El País se opta por presentar las noticias en la primera plana de forma continua, sin ningún tipo de estructuración, así como reservar un espacio para "secciones" en la parte superior derecha de la pantalla.

Para el estudio de la distribución formal de las versiones para móvil se hizo un seguimiento de las secciones que los diferentes medios destacaban para sus lectores en movilidad. Mientras que en las webs todas cobran igual relevancia en los diferentes casos estudiados, en las versiones móviles de los cibermedios solamente se repiten y destacan dos de ellas por unanimidad: deportes e internacional. Este aspecto, principalmente en lo que se refiere a la sección "deportes", marca una de las principales tendencias adoptadas por los medios en la nueva plataforma móvil: valorizar aquellas secciones temáticas en las que prima la información en directo, sin dejar de tener en cuenta también las predilecciones de los usuarios. Este es el caso de The Guardian (figura 9) que incorpora en su página principal, dentro de la sección de deportes, reportajes en vivo en los que se informa minuto a minuto sobre determinados acontecimientos. 


\section{Distribución de secciones}

\begin{tabular}{|c|c|c|c|c|}
\hline & Le Monde & Reppublica & El País & The Guardian \\
\hline \multirow{3}{*}{$\begin{array}{l}\text { 岂 } \\
\text { 岂 }\end{array}$} & \multirow{3}{*}{$\begin{array}{l}\text { - Elecciones } \\
\text { - Videos } \\
\text { - Internacional } \\
\text { - Política } \\
\text { - Economía } \\
\text { - Sociedad } \\
\text { - Planeta } \\
\text { - Tecnología } \\
\text { - Estilo } \\
\text { - Deporte } \\
\text { - Mundo del automóvil } \\
\text { - Ideas } \\
\text { - Ciencias } \\
\text { - Educación } \\
\text { - Cultura } \\
\text { - “Vosotros” }\end{array}$} & $\begin{array}{l}\text { - Inicio } \\
\text { - Deportes } \\
\text { - Bolsillo } \\
\text { - Última hora } \\
\text { - Crónica } \\
\text { - Internacional } \\
\text { - Política } \\
\text { - Ciencias } \\
\text { - Medio Ambiente }\end{array}$ & $\begin{array}{l}\text { - Internacional } \\
\text { - España } \\
\text { - Opinión } \\
\text { - Economía } \\
\text { - Deportes } \\
\text { - Otras noticias } \\
\text { - Fotos }\end{array}$ & \multirow{3}{*}{$\begin{array}{l}\text { - Mundo } \\
\text { - Cultura } \\
\text { - Estilos de vida } \\
\text { - Tecnología } \\
\text { - Medio Ambiente } \\
\text { - Deporte } \\
\text { - Política } \\
\text { - Medios } \\
\text { - Fútbol } \\
\text { - Galerías } \\
\text { - Opinión } \\
\text { - Blogs } \\
\text { - Negocios } \\
\text { - Trabajo } \\
\text { - Leer más }\end{array}$} \\
\hline & & $\begin{array}{l}\text { SERVICIOS: } \\
\text { - Cine } \\
\text { - Restaurantes } \\
\text { - Tiempo } \\
\text { - Anuncios }\end{array}$ & \multirow{2}{*}{$\begin{array}{l}\text { SERVICIOS: } \\
\text { - Tempo } \\
\text { - Tráfico } \\
\text { - Cartelera } \\
\text { - Sorteos } \\
\text { - Prog.TV } \\
\text { - Cadena Ser }\end{array}$} & \\
\hline & & $\begin{array}{l}\text { Tiene ediciones } \\
\text { locales }\end{array}$ & & \\
\hline
\end{tabular}

Figura 8: Distribución de secciones. Fuente: Elaboración propia

La importancia de los contenidos actualizados también se corroboró con la comprobación de las fechas y la hora presentes tanto en la portada como dentro de cada pieza informativa. La Repubblica es el único medio que no dispone de dicha aclaración mientras que los otros tres cibermedios si que destacan por la actualización de sus noticias.

El uso de la multimedialidad es uno de los factores que incorporan todos los medios estudiados aunque hay que destacar que existen claras diferencias entre ellos. The Guardian aposta por la inclusión de galerías de imágenes, vídeos de corta duración y utiliza los elementos multimedia como recurso para jerarquizar sus informaciones a partir del aumento o reducción de su tamaño. Le Monde, en cambio, se decanta por el uso casi exclusivo de fotografías en las que la dinámica se centra en destacar una sola información en portada. El País es el cibermedio que más arriesga con el uso del vídeo. Como se puede comprobar en el siguiente gráfico, The Guardian y Le Monde acompañan la totalidad de sus informaciones en

DOI: ri14.v11i2.586 | ISSN: 1697-8293 | Año 2013 Volumen 11 N² 2 | ICONO14 
portada con algún elemento multimedia mientras que El País o Repubblica optan por diferenciar sus contenidos en la primera página.

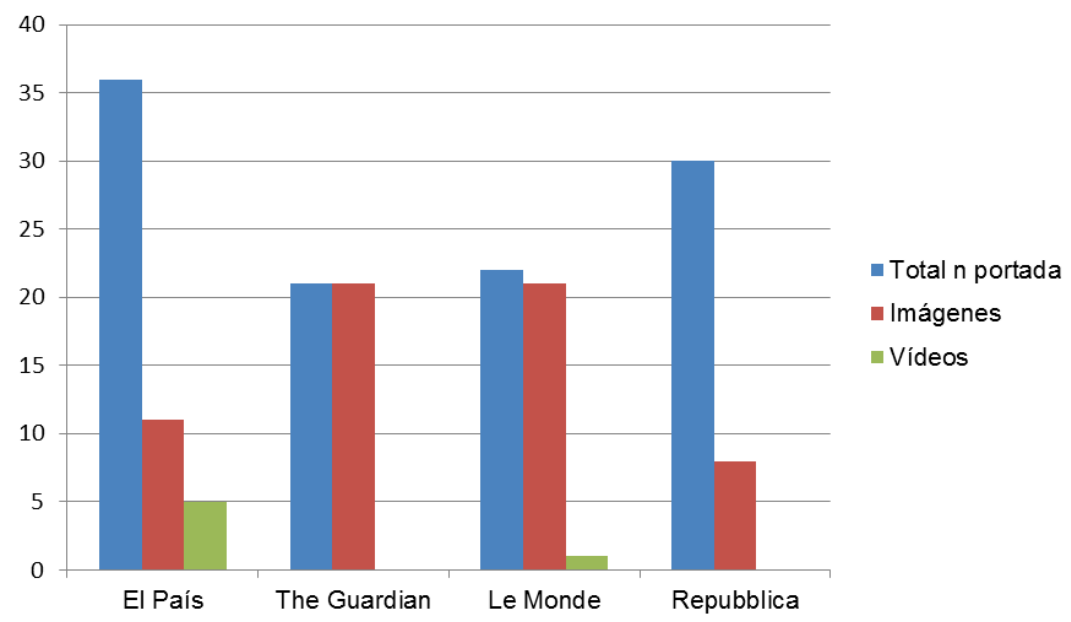

Figura 9: Distribución de noticias, imágenes y vídeos en portada. Fuente: Elaboración propia

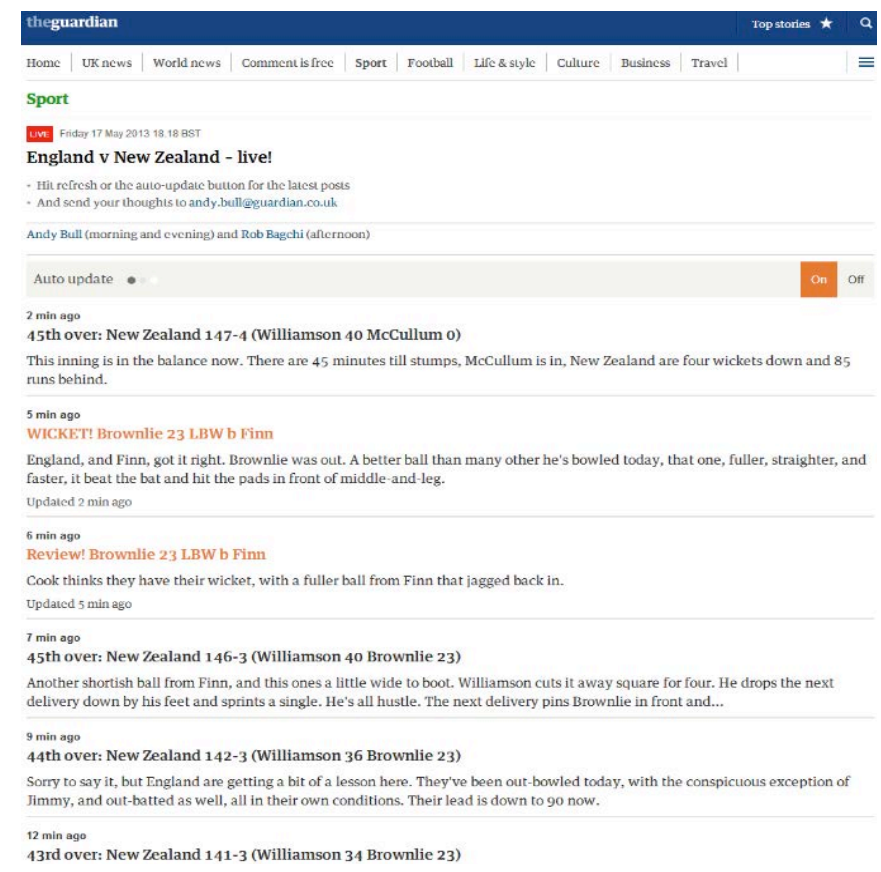

Figura 10: Sección deportes en The Guardian. Fuente: Elaboración propia a partir de captura de la web móvil de The Guardian 
El objetivo de este estudio era examinar también si las versiones móviles de los principales medios de referencia europeos descuidaban aspectos como la autoría, tal y como sucedía en el caso gallego, y si se tenía en consideración al usuario como partícipe de los contenidos, bien a través de redes sociales o de otras herramientas de retroalimentación. Ambas cualidades están presentes en los cuatro cibermedios, algo que contrasta con los primeros pasos dados por los medios gallegos en la plataforma móvil.

A pesar de las capacidades de las que disponen como herramienta comunicativa, los móviles cuentan con una serie de obstáculos que dificultan el pleno desarrollo de la producción de contenidos informativos: la dependencia de los operadores telefónicos, los fabricantes de hardware y software y su influencia, la dificultad para establecer una métrica estándar del tráfico de usuarios que acceden a los contenidos móviles, los altos precios de tarifas de banda ancha móvil y la falta de referentes previos (Sánchez y Aguado, 2010, p.17).

En el ámbito de la telefonía móvil, mercado de rápido crecimiento y expansión social, la empresa que domine el mercado llegará a controlar de alguna manera gran parte del sector tecnológico. El mercado actual se reparte entre dos empresas principales: Google y Apple.

El sector de las telecomunicaciones en España afronta grandes retos. Además de la crisis financiera global y del entorno de recesión, la intensidad de la competencia, definida por la guerra de precios, tuvo especial significación durante los últimos años. Frente a la estructura tradicional en la que los operadores de redes eran a su vez los proveedores de servicios sobre las infraestructuras, en la actualidad se percibe un desplazamiento del protagonismo en la cadena de redes a las apps, servicios y dispositivos, quedando la gestión de la red con un papel secundario y con menor valor recibido. Esto obliga a los operadores a competir en la provisión de servicios con otros agentes del sector de las TIC y los desarrolladores se ven en la necesidad de pensar en la mejor fórmula para adaptarse a las cada vez más exigentes necesidades del mercado.

En este panorama cambiante en el que se ven afectadas las empresas periodísticas cobra especial relevancia el papel del usuario. El norteamericano Robert Picard (2006), estudioso de la economía de medios, sitúa al usuario en este entorno en el que adquiere una nueva dimensión: se convierte de alguna manera en un cliente de las empresas (fabricantes, operadores) más que del propio medio en cuestión.

DOI: ri14.v11i2.586 | ISSN: 1697-8293 | Año 2013 Volumen 11 N² 2 | ICONO14 
Picard invita a reflexionar sobre este aspecto y sobre como las empresas periodísticas se dejan llevar por intereses ajenos a los propios consumidores. Uno de los desafíos principales que encara el periodismo se relaciona con la "creación de valor para los ciudadanos y la sociedad y esto supone destacar nuevamente la información que ayude en la vida de las personas, fortaleciéndolos como ciudadanos y ayudándoles a participar e implicarse socialmente". La clave es, en palabras de Picard, situarse en un escenario en el que "se apostará más por los proyectos que por las empresas".

\subsection{Nuevos usuarios: prosumidores}

La telefonía móvil no solo alteró el panorama periodístico sino que repercutió en los propios usuarios otorgándoles a estos un papel activo en el proceso comunicativo. El tradicional modelo bidireccional dio paso, gracias a la introducción de la Web 2.0, a otro en el que el receptor deja de ser pasivo, asumiendo tareas relativas a la producción y la creación de contenidos. De alguna manera, los dispositivos móviles pusieron al usuario en el lugar del periodista y comenzó a cobrar nuevamente relevancia la participación ciudadana y el periodismo cívico.

En la nueva sociedad ubicua se extiende la figura del prosumidor, término inglés resultado de la fusión de prosumer (productor) y consumer (consumidor). La palabra ya había sido enunciada por el teórico Mc Luhan en su momento y Alvin Toffler también la había utilizado para referirse a los individuos que actúan no solo como consumidores sino también como productores (Arroyo, 2010, p.10). Este nuevo usuario exige contenidos on demand, es decir, servicios de información disponibles para todos en cualquier tiempo y lugar, algo acorde con el escenario ubicuo actual (Islas, 2012, p.4).

La "sociedad de la ubicuidad" hace referencia a una "sociedad en la que cualquier persona puede consumir, en cualquier momento y en cualquier lugar, una amplia gama de servicios a través de diversos dispositivos terminales y redes de banda ancha. Su lema es: cualquier persona, en cualquier lugar, en cualquier momento" (Islas, 2008, p.71).

Islas afirma que en el escenario de la comunicación móvil se estimula la creatividad y la autonomía (p.27). La figura del nuevo usuario es determinante en los procesos de "remediación". Este término se enmarca dentro de la teoría de la

ICONO14 | Año 2013 Volumen 11 N² | ISSN: 1697-8293 | DOI: ri14.v11i2.586 
"ecología de medios" y hace referencia al mismo proceso de evolución tecnológica y a como los medios progresan con el propósito, consciente o no, de hacerse más similares al hombre (p.30).

A nivel social, los propios usuarios experimentaron un cambio y se convirtieron en lo que Howard Rheingold denominó "multitudes inteligentes". Según Rheingold (2004) “los teléfonos móviles dieron origen a un nuevo tipo de multitud, una multitud con conciencia propia de movimiento dirigido hacia un objetivo común.

Las principales tendencias sociales que fueron transformadas por las comunicaciones móviles fueron las siguientes (Telefónica, 2011):

- Transformación del tiempo y del espacio

- Siempre comunicados. El always on

- Atracción por lo próximo

- Personalización: El carácter identitario de privacidad que permite el teléfono contribuye a ese grado de individualismo que caracteriza a las comunicaciones móviles

- Relaciones sociales más complejas. Muchos sociólogos aluden a que gracias a la telefonía móvil se refuerzan los lazos sociales a favor de la cohesión

- (Des) igualdad social. Este aspecto está intrínsecamente relacionado con las habilidades tecnológicas de los usuarios en la brecha generacional. Los dispositivos móviles requieren de un mínimo conocimiento para su uso y de unas condiciones estructurales óptimas, con acceso a banda ancha de las que muchos países no pueden beneficiarse.

La transformación global que ocasiona el dispositivo móvil en la industria periodística se deja notar también en el eslabón profesional. El móvil, además de un soporte de contenidos, emerge como una de las principales herramientas para la cobertura periodística. La polivalencia permite explicar estas mutaciones cuyo punto de partida es la adaptación a un entorno cada vez más descentralizado por la participación de la audiencia, que demanda más precisión y exigencia en la gestión de las fuentes, se mueve en la inmediatez y busca una mayor personalización y ubicuidad en los contenidos. 


\section{Conclusiones}

Después de situar, en líneas generales, el escenario de la comunicación móvil se observa que existe un cierto paralelismo entre los inicios del periodismo móvil y los del ciberperiodismo. La evolución de la prensa digital se caracterizó por un desarrollo evolutivo marcado principalmente por cuatro fases: volcado, hipertexto, servicios multimedia y comercio electrónico y contenidos exclusivos y elementos interactivos.

La comunicación móvil está hoy en día en una fase difusa, entre la primera y la segunda categoría. La mayor parte de los estudiosos del tema confían en las posibilidades que tiene el teléfono móvil como transmisor de información y creen que la sociedad actual está preparada para hacer del móvil un nuevo medio de comunicación. Bien es cierto que hay que luchar con limitaciones que van desde la garantía de conectividad hasta la clara definición de los modelos de negocio o la articulación de un sistema de producción de contenidos específicos y adaptados al nuevo soporte.

Los diferentes análisis llevados a cabo hasta el momento nos aportan la visión de que el teléfono móvil como medio está aún sin explotar y las empresas mediáticas no parecen confiar plenamente en sus posibilidades. Lo vemos en el caso de los medios de comunicación analizados durante el último año. La seña de identidad, desde el punto de vista formal, de las versiones móviles de los medios descansa en el diseño y en la distribución de las páginas pero no existen avances a nivel de producción.

Las empresas mediáticas deben ser conscientes de que más de un cuarto de la población, en torno al 27\%, accede a noticias a través de los móviles. Necesitan fijarse en los patrones de consumo de estos consumidores que son además propensos a recurrir a organizaciones de noticias directamente a través de aplicaciones 0 páginas de inicio, en lugar de búsquedas o recomendaciones.

El análisis hecho en este trabajo de los productos móviles permite concluir que los cibermedios están realizando sus incursiones tímidamente en los dispositivos móviles. En el caso gallego, aspectos como la carencia de la firma de los periodistas en informaciones en la versión móvil, la ausencia de elementos de contacto que refuercen la interacción entre lectores y medios o la homogeneidad en la presentación de las noticias es un claro síntoma de la escasa consideración que recibe 
el nuevo soporte. El caso de los cibermedios europeos se muestra más proclive a la explotación de las especificidades del móvil como plataforma aunque en determinados casos el desequilibrio en la utilización de la multimedialidad, la falta de exclusividad de las informaciones para las ediciones móviles o la ausencia de una marca de identidad propia para el nuevo soporte manifiestan las debilidades de los cibermedios en el contexto de la movilidad.

Por el contrario, los resultados permiten hablar de la eclosión de una serie de tendencias que sientan las bases alrededor de las cuales girarán los contenidos en movilidad. Por una parte, la predilección por las secciones de local y deportes, tal y como se advirtió en los medios gallegos y europeos y, por otra, la actualización de contenidos. La brevedad y la instantaneidad cobrarán especial relevancia en los productos concebidos para la cuarta pantalla.

Los retos de futuro se sitúan, entonces, en torno a varias propiedades: personalización, actualización, adaptación a la segmentación de públicos, aprovechamiento del potencial tecnológico del dispositivo móvil (GPS, geolocalización, realidad aumentada), y búsqueda de nuevos formatos.

En general se percibe cierto grado de interés por parte de los principales cibermedios europeos de referencia en trasladar sus contenidos en las plataformas móviles, sobre todo contrastado con el de los medios gallegos tan solo dos años antrás. A pesar de esto, las principales versiones móviles analizadas destacan por noticias extensas en las que predomina el texto y en las que no existe diferenciación alguna con su equivalente en la edición web. A nivel de contenidos no se contempla la especificidad del nuevo soporte mientras que a nivel formal se vislumbran los primeros pasos de lo que va a ser el nuevo periodismo en línea.

El futuro para las principales empresas mediáticas es el de adaptarse a los nuevos tiempos, pero no solo eso. Subirse al tren de la cuarta pantalla requiere un cambio de mentalidad que conviene tener en cuenta. El móvil es el medio de masas por antonomasia, todo el mundo lleva uno en el bolsillo. Trasladar el periódico a la pequeña pantalla requiere un esfuerzo mayor pero si se realiza con éxito esto repercutirá notablemente en la imagen $\mathrm{y}$, por consiguiente, en la audiencia del medio en cuestión. Además, en un contexto en el que los cambios son constantes y la situación económica obliga a reorientar los modelos de negocio de las empresas resulta necesario aprovechar las oportunidades que nos brinda la telefonía móvil para el escenario de la comunicación, una tecnología que refuerza, además, la ló-

DOI: ri14.v11i2.586 | ISSN: 1697-8293 | Año 2013 Volumen 11 N² 2 | ICONO14 
gica de la sociedad red y que se percibe como uno de los principales desafíos del periodismo del momento.

\section{Referencias}

Aguado, J.M (2012). Los gigantes, los ratones y el pastel: Las industrias culturales y el entorno de la movilidad. En MobileCommunication 2012. Experiències i recerques sobrecomunicació mòbi. Vic: Universitat de Vic. Grup de Recerca. Recuperado de: [http://es.scribd.com/doc/91859208/ Comunicacion-movil-2012-experiencias-e-investigaciones]

Aguado, J.M., y Martínez, I. (2008). La cuarta pantalla: industrias culturales y contenido móvil. En Aguado, J.M. y Matínez, I.J. (coords.), Sociedad móvil: Tecnología, identidad y cultura. Madrid: Biblioteca Nueva Ahonen, T. (2008). Mobile as 7th of the Mass Media: Cellphone, cameraphone, iPhone, smartphone. Londres: FuturetexT

Arroyo, L. (2010). En proceso de adaptación. La empresa móvil de andar lento.

Revista Telos. Cuadernos de Comunicación e Innovación, 83, 50-61

Boczkowski, P. (2006). Digitalizar las noticias: Innovación en los diarios online.

Buenos Aires: Manantial

Canavilhas, J. (2009). Contenidos informativos para móviles: estudio de aplicaciones para iPhone. Revista Textual\&Visual Media, 2, 61-80

Cebrián, M. y Flores, J. (2011). Periodismo en la telefonía móvil. Madrid: Fragua Comscore (2013). Europe Future in Focus (en línea). Recuperado de: http://www. comscore.com/esl/Insights/Presentations_and_Whitepapers/2013/2013_ Europe_Digital_Future_in_Focus

Comscore (2011). Europe Digital Year in Review (en línea). Recuperado de: http:// www.comscore.com/Press_Events/Presentations_Whitepapers/2011/2010_ Europe_Digital_Year_in_Review

Costa, C. (2008). Estado del arte de la comunicación móvil en España. Aportaciones realizadas y retos de futuro. Revista de Comunicación Vivat Academia, Especial, 1048-1058

Fidalgo, A. (2009). 0 celular de Heidegger - comunicaçao ubíqua e distância existencial. Revista Matrizes, 3, 81-98 
Fumero, A.M. (2010). Introducción: la red en el móvil. Revista Telos, 83, 43-49 Islas, Octavio (2008). El prosumidor. El actor comunicativo en la sociedad de la ubicuidad. Revista Palabra-Clave, 1, 29-39

Merrill, John (1968). The Elite Press. Great Newspapers of the World. Nueva York:

Pitmann Pub. Corp.

Oksman, V. y Rautiainen, P. (2002). Toda mi vida en la palma de mi mano. La comunicación móvil en la vida diaria de niños y adolescentes de Finlandia. Revista Estudios de la Juventud, 57, 25-32

Picard, R. (2006): Journalism, Value Creation and the Future of News Organizations (en línea). Disponible en: http://www.robertpicard.net/ PDFFiles/ValueCreationandNews0rgs.pdf

Rheingold, R (2003). Multitudes inteligentes. Barcelona: Gedisa Rojo, P.A. (2008). El acceso a la información en la era digital: situación actual y perspectivas. Revista Comunicación, 6, 159-172

Sánchez, E. y, Aguado, J.M (2010). Dispositivos móviles y convergência digital en los grupos de comunicación españoles: la perspectiva de los profesionales, II Congreso Internacional AE-IC "Comunicación y Desarrollo en la Era Digital". Málaga

Scolari, C.A., Aguado, J.M. y Feijoo, C. (2012). Mobile media: Towards a definition and taxonomy of contents and application. International Journal of Interactive Mobile Technologies. Revista International Journal of Interactive Mobile Technologies IJIM, 2

Silva, A (2011). Os xornais galegos nos dispositivos móbiles. Características textuais e formais dos primeiros pasos (2009-2011). (Tesina fin de máster). Universidad Santiago de Compostela. Santiago de Compostela

Silva, A (2012). Periodismo en dispositivos móviles: perspectiva de la lenta incorporación por los medios de Galicia. En Actas del XXIII Congreso del periodismo digital, (11-26). Huesca: Universidad de Periodismo de Huesca Telefónica, 2011. La Sociedad de la Información en España 2011. Ariel, FundaciónTelefónica.

Vacas, F. (2007). Telefonía móvil: la cuarta ventana. Revista ZER, 23, 199-217. Varela, J. (2012). La información se consume en móvil, redes sociales y vídeo (en línea). Recuperado de: http://www.periodistas21.com/2012/09/lainformacion-se-consume-en-movil.html. 